\title{
First Dose Phenomenon in a Scorpion Sting Patient Being Treated with Prazosin: A Case Report
}

\author{
Reshma Manik, Jagruti Arun Pashte, Varsha Iranna Dalal*, Prasad Bali \\ Department of Pharmacy Practice, KLE College of Pharmacy, Vidyanagar, Hubballi, Karnataka, INDIA.
}

\begin{abstract}
Prazosin, an antihypertensive drug, has found prominent importance in managing scorpion envenomation in recent times. It is being used off the label however studies have found to be very effective in the management of scorpion sting. This is a case report of the prazosin-induced first dose phenomenon in a 4-year-old patient treated for scorpion sting. In hypertensive patients, the first dose phenomenon is a widely reported adverse effect due to prazosin however in scorpion sting patients it is rarely reported. A sudden fall in blood pressure can be life-threatening, more so in the pediatric population. Educating the rural public about the importance of taking medical consultation for a scorpion sting, availability of treatment, and protocol for the management of the scorpion sting is the need of the hour.
\end{abstract}

Key words: First dose phenomenon, Prazosin, Scorpion sting, Patient Education.

\section{INTRODUCTION}

Scorpions are arachnids belonging to order Scorpions, most of the deadly species to humans belong to family Buthidae. ${ }^{1}$ About 1988 species of scorpions are known worldwide, of which 113 species belonging to 25 genera are documented to be found in India. ${ }^{2}$

Scorpion venom is a complex made up of mucopolysacharides, peptides, proteins, phospholipase, enzyme inhibitors, toxins, and histamine. It is a neuronal transmission blocking complex, which functions by binding to the voltage gated ion channels thereby inhibiting their inactivation. ${ }^{3}$

Scorpion envenomation is an important public health issue more prevalent in tropical and subtropical countries. It is a commonly occurring incident in rural and sub-urban localities of India. The global annual incidence of scorpion sting is found to be 1.5 million, however, in India under reporting remains a matter of concern since most cases aren't brought to a medical facility. ${ }^{4}$ In pediatric population, owing to their smaller body surface area, scorpion sting remains a treacherous medical emergency, which may lead to multiple organ failure and in rare cases even death. It is a potent sympathetic stimulator. Complication of envenomation may manifest as pulmonary edema, myocarditis, cardiogenic shock, acute kidney injury and other neurological, cardiac and respiratory complication. Pain at the sting site and tachycardia are the most prevalent symptoms. ${ }^{5}$

Prazosin- a quinazoline derivative is a competitive post-synaptic alpha 1 adrenoreceptor blocker; it causes a reduction in total peripheral resistance and direct relaxation of vascular smooth muscles thereby helping in countering the vasoconstriction due to accretion induced by endothelins. It decreases the blood pressure, pre load and after load without affecting the heart rate. It also prevents myocardial injury by phosphodiesterase enzyme inhibition. Prazosin also maintains the blood glucose levels by suppressing the inhibition of insulin
DOI: 10.5530/ijopp.14.4.61

Address for correspondence: Dr. Varsha Iranna Dalal KLE College of Pharmacy, Vidyanagar, Hubballi-580031, Karnataka, INDIA.

Phone no: +91-8095623409 Email id: dalalvarsha59@ gmail.com

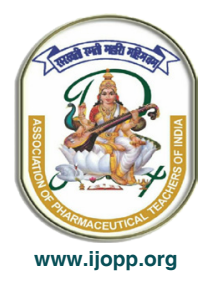


secretion due to scorpion venom. Therefore it is used as first line of management in scorpion sting. ${ }^{6}$

Prazosin can be administered regardless of blood pressure given there is no hypervolemia. It is known to cause adverse effects like palpitations, orthostatic hypotension, dizziness, headache; nausea etc. Orthostatic hypotension can be defined as steady reduction in blood pressure exceeding $20 \mathrm{mmHg}$ systolic or $10 \mathrm{mmHg}$ diastolic within 3 minutes of standing up from supine. Therefore the patient should be advised to be in lying posture during the administration of prazosin.

Here is a case of prazosin induced first dose phenomenon in a pediatric patient who was being treated for scorpion sting.

\section{CASE DESCRIPTION}

A 4 year old, pediatric, female patient was rushed to emergency department of Vivekananda General Hospital, Hubli, with alleged history of scorpion sting over dorsal part of her left lower limb. On examination, the child was drowsy and tachycardia with a heart rate of $180 \mathrm{bpm}$. A careful examination of the sting site revealed erythema accompanied with edema. At the time of admission her blood pressure was noted to be $140 / 100 \mathrm{mmHg}$. A marked elevation in RBS $(280 \mathrm{mg} / \mathrm{ml})$ was also observed. Based on ECG and elevated BP the child was diagnosed with myocarditis. The patient's chest X-ray was unremarkable showing no signs of pulmonary edema; however there was an elevated serum creatinine level of $2.6 \mathrm{mg} / \mathrm{dl}$ on day one suggesting of acute kidney injury, secondary to scorpion sting.

The patient was started with IVF@ 50 ml/hr.-NS, Inj. Pantaprazole-20 mg OD; Inj.Cefotaxime-500 mg IV BD; Tab. Prazosin $1 \mathrm{mg}^{1 / 2}$ TID.

The patient's blood pressure, heart rate and oxygen saturation were noted every hour, gradual resolution of hypertension and tachycardia was observed. The child was kept in supine position throughout observation despite which she developed first dose phenomenon, with remarkable fall in blood pressure and heart rate at the end of fourth hour. (Table 1) She was resuscitated with normal saline (at $20 \mathrm{ml} / \mathrm{kg}$ ) and was stabilized. Her fourth hourly GRBS monitoring on first day of admission showed following pattern. (Table 2)

The patient was kept under observation at the hospital for a period of three days. Serum creatinine levels were monitored for three consecutive days, which showed a decline towards normal range. (Table 3)
Table 1: Hourly blood pressure (NIBP) and heart rate of the patient.

\begin{tabular}{ccc} 
Time & Blood pressure & Heart rate \\
\hline On admission & $140 / 100 \mathrm{mmHg}$ & $180 \mathrm{bpm}$ \\
First hour & $145 / 102 \mathrm{mmHg}$ & $189 \mathrm{bpm}$ \\
Second hour & $130 / 100 \mathrm{mmHg}$ & $140 \mathrm{bpm}$ \\
Third hour & $110 / 90 \mathrm{mmHg}$ & $90 \mathrm{bpm}$ \\
Fourth hour & Hypotensive & Bradycardia \\
\hline
\end{tabular}

Table 2: Fourth hourly random blood glucose monitoring.

Grbs $4^{\text {th }}$ Hourly

$280 \mathrm{mg} / \mathrm{dl}$

$243 \mathrm{mg} / \mathrm{dl}$

$212 \mathrm{mg} / \mathrm{dl}$

$190 \mathrm{mg} / \mathrm{dl}$

$160 \mathrm{mg} / \mathrm{dl}$

Table 3: Serum creatinine levels during three days of admission.

\begin{tabular}{cc} 
Days & Serum creatinine \\
\hline Day 1 & $2.6 \mathrm{mg} / \mathrm{dl}$ \\
Day 2 & $2.1 \mathrm{mg} / \mathrm{dl}$ \\
Day 3 & $1.8 \mathrm{mg} / \mathrm{dl}$ \\
\hline
\end{tabular}

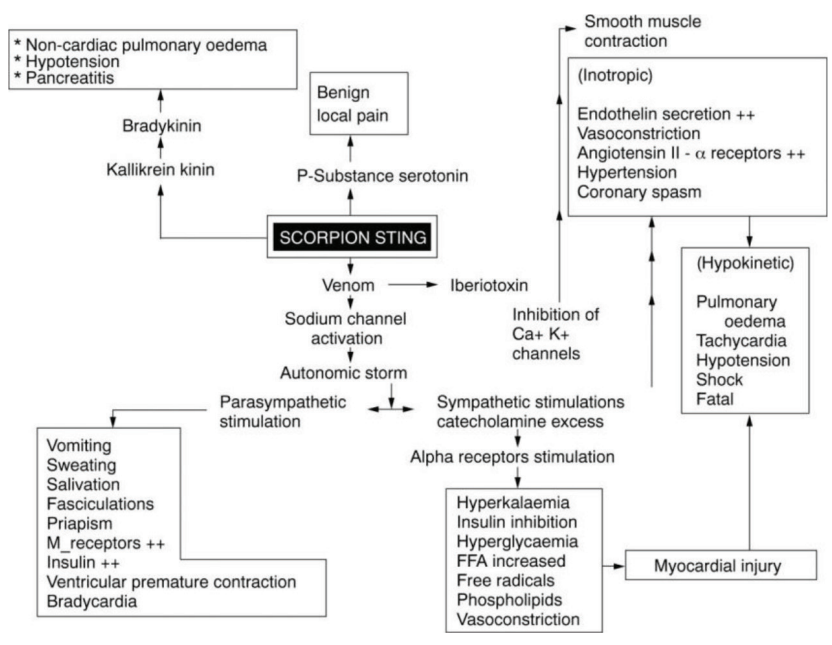

Figure 1: Pathogenesis of scorpion venom in human beings. ${ }^{12}$

\section{DISCUSSION}

The first dose phenomenon can be characterized by a group of transient symptoms, typically palpitations, orthostatic hypotension, dizziness, lightheadedness. ${ }^{8}$ First dose phenomenon after the administration of prazosin is widely reported. There is reversible competitive antagonism of $\alpha 1$-adrenorecptors at the blood vessels that regulate the sympathetic tone and venodialation that Indian Journal of Pharmacy Practice, Vol 14, Issue 4, Oct-Dec, 2021 
reduces the preload and thereby impairing the cardiac output, this is believed to be the reason ascribed to the occurrence of first dose phenomenon. ${ }^{9}$ (Figure 1$)^{12}$

In pediatrics, prazosin at dose of $30 \mu \mathrm{g} / \mathrm{kg} / \mathrm{dose}$ has been shown to be effective as first line treatment for scorpion sting in many trials. It can be used regardless of the blood pressure however its administration is not recommended in presence of hypovolemia. To avoid the First dose phenomenon it is recommended that the child should not be lifted up at least for a period of 3 hrs. ${ }^{10}$ Aggressive fluid resuscitation by IV push may help in achieving desired blood pressure and heart rate. For initial fluid resuscitation Isotonic Normal Saline or Ringers Lactate boluses of $20 \mathrm{~mL} / \mathrm{kg}$ over $10-15 \mathrm{~min}$ is recommended. It is easily available, has low cost and has lesser side effects. However vasopressors can be used as last resort for management of hypotension when fluid therapy is ineffective.

Some studies have shown the effectiveness of anti-venom administration along with Prazosin in terms of faster recovery and reduced hospital stay. Each scorpion has their own array of elements which they use for their defense. Scorpion anti-venom has been approved for usage in India since 2002, however its cost, specificity, adverse effects and its immediate availability in rural areas affects their rationality. ${ }^{11}$

\section{CONCLUSION}

The authors recommend for the proper public awareness as scorpion stings is mainly observed affecting the pediatric population, especially in the south Indian region, owing to the geography and climatic conditions. Awareness among the general public, on right management of scorpion sting and the importance of it being treated at a medical facility will avoid fatalities. Provision of adequate facilities at primary health care centers will ease the management of scorpion sting.

\section{ACKNOWLEDGEMENT}

The author thanks KLE College of Pharmacy, Hubballi and Vivekananda General Hospital, Hubli for all the support.

\section{CONFLICT OF INTEREST}

The authors declare no potential conflicts of interest with respect to research, authorship, and/or publication of this article.

\section{REFERENCES}

1. Cesaretli Y, Ozkan O. Scorpion stings in Turkey: epidemiological and clinical aspects between the years 1995 and 2004. Rev Inst Med Trop Sao Paulo. 2010;52(4):215-20. doi: 10.1590/s0036-46652010000400010, PMID 21748231.

2. Joseph. Baby and George, Jency. Int J Toxicol Pharmacol Res. 2012. Scorpion toxins and its applications;4:57-61.

3. Al-Asmari AK, Kunnathodi F, Al Saadon K, Idris MM. Elemental analysis of scorpion venoms. J Venom Res. 2016;7:16-20. PMID 27826410.

4. Al Abri S, Al Rumhi M, Al Mahruqi G, Shakir AS. Scorpion sting management at tertiary and secondary care emergency departments. Oman Med J. 2019;34(1):9-13. doi: 10.5001/omj.2019.02, PMID 30671178.

5. Bawaskar HS, Bawaskar PH. Prazosin in management of cardiovascular manifestations of scorpion sting. Lancet. 1986;1(8479):510-1. doi: 10.1016/ s0140-6736(86)92979-x, PMID 2869255.

6. Bawaskar HS, Bawaskar PH. Indian red scorpion envenoming. Indian J Pediatr. 1998;65(3):383-91. doi: 10.1007/BF02761131, PMID 10771989.

7. RIECKERT H. Orthostatic hypotension: how to avoid it during antihypertensive therapy. Am J Hypertens. 1996;9(11):155S-9S. doi: 10.1016/08957061(96)00291-9, PMID 8931848.

8. Lin MS, Hsieh WJ. Prazosin-induced first-dose phenomenon possibly associated with hemorrhagic stroke: A report of three cases. Drug Intell Clin Pharm. 1987;21(9):723-6. doi: 10.1177/106002808702100910, PMID 3652934.

9. Take H, Shibata K, Awaji T, Hirasawa A, Ikegaki I, Asano T, Takada T, Tsujimoto G. Vascular a1-adrenoceptor Subtype Selectivity and a1-BlockerInduced Orthostatic Hypotension. Jpn J Pharmacol. 1998;77(1):61-70. doi: 10.1254/jjp.77.61, PMID 9639061.

10. Shoreit A, Eltayeb A, Ali S. Role of prazosin in management of scorpion sting in pediatrics: a comparative study. J Curr Med Res Pract. 2019;4(2):174. doi: 10.4103/JCMRP.JCMRP_132_18.

11. Bawaskar HS, Bawaskar PH. Efficacy and safety of scorpion antivenom plus prazosin compared with prazosin alone for venomous scorpion (Mesobuthustamulus) sting: randomised open label clinical trial. BMJ. 2011;342(jan 05-3):c7136-. doi: 10.1136/bmj.c7136, PMID 21209062.

12. Laraba-Djebari F, Adi-Bessalem S, Hammoudi-Triki D. Scorpion venoms: pathogenesis and biotherapies. Scorpion Venoms. 2014:63-85. 